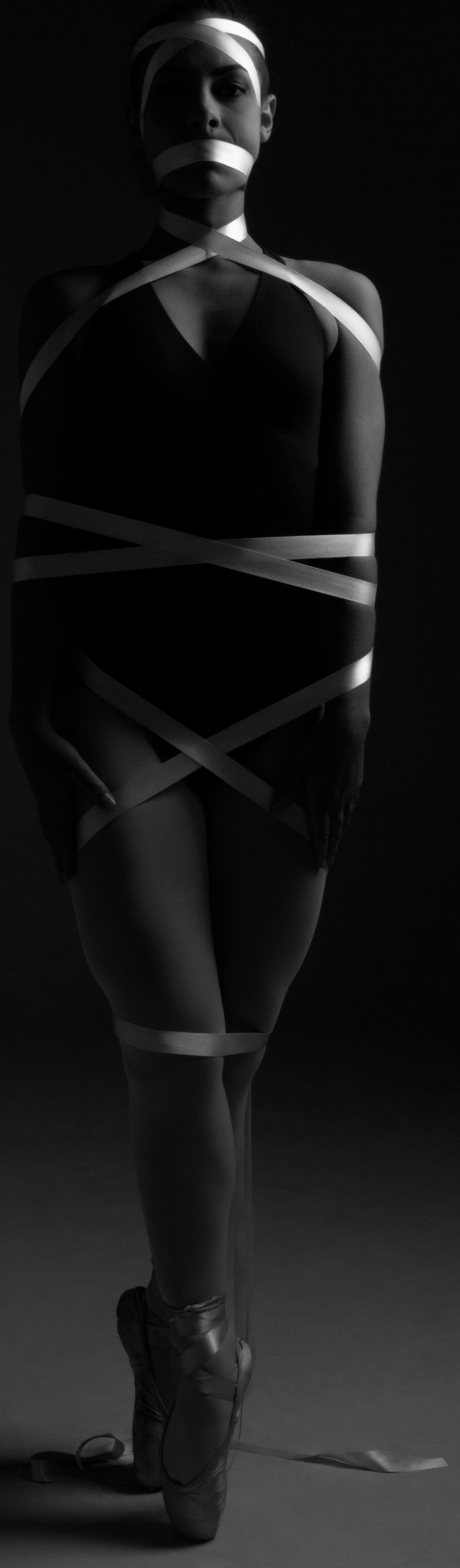




\title{
La práctica dancística como una estrategia dentro del contexto educativo para el desarrollo de un cuerpo más consciente y atento
}

\section{Artículo de reflexión}

Recibido 01 de diciembre de 2016 Aceptado el 18 de junio de 2017

\section{Laura Oyuela Morales}

\author{
Universidad Distrital Francisco José de Caldas
}

lauh-17@hotmail.com

@(1)@

Cómo citar este artículo: Oyuela, L [2017]. La práctica dancística como una estrategia dentro del contexto educativo para el desarrollo de un cuerpo más consciente y atento, Calle14 revista de investigación en el campo del arte, 12[22], 268-279

DOl: https://doi.org/10.14483/21450706.12358

\section{Resumen}

El presente artículo aborda la práctica dancística como un escape a los modelos de cuerpo inmóvil construidos por la sociedad, reflexionando acerca de las formas en que la danza puede ser un medio óptimo para el desarrollo del cuerpo en movimiento que hace parte de todos los ámbitos de la vida y cuya praxis puede ser introducida en los sistemas educativos como un eje transversal al aprendizaje y al reconocimiento del mundo. Se plantea entonces el siguiente problema: ¿Cómo la práctica dancística puede ser una estrategia dentro del contexto educativo para el desarrollo de un cuerpo más consciente y atento? Cuestión que es tratada desde una metodología descriptiva y reflexiva fundamentada en la revisión teórica de los conceptos de cuerpo, movimiento, modelos culturales y pedagógicos, y danza, para finalmente sugerir la práctica dancística como una estrategia pedagógica óptima para la construcción de un cuerpo consciente y atento.

\section{Palabras claves}

Cuerpo, danza, disciplina, educación, movimiento, reconocimiento corporal. 


\title{
The Practice of Dance as a Strategy Within the Educational Context for the Development of a More Conscious and Attentive Body
}

\begin{abstract}
This article approaches the practice of dance as an escape from the models of the still body built by society, reflecting on the ways in which dance can be an optimal medium for the development of the body in movement that is part of all areas of life and whose praxis can be introduced in the educational systems as a transversal axle to the learning and the recognition of the world. The following problem arises: How can dance practice be a strategy within the educational context for the development of a more conscious and attentive body? A question that is treated from a descriptive and reflexive methodology based on the theoretical revision of the concepts of body, movement, of cultural and pedagogical models, and of dance, to finally suggest the practice of dance as an optimal pedagogical strategy for the construction of a conscious and attentive body.
\end{abstract}

\section{Keywords}

Body, dance, discipline, education, movement, body recognition.

La pratique de la dance comme une stratégie dans le contexte éducatif pour le développement d'un corps plus conscient et attente

\section{Résumé}

Cet article aborde la pratique de la danse comme une évasion des modèles du corps immobile construits par la société, en réfléchissant sur les façons dont la danse peut être un moyen optimal pour le développement du corps en mouvement qui fait partie de tous les domaines de la vie et dont la praxis peut être introduite dans les systèmes éducatifs comme un axe transversal à l'apprentissage et à la reconnaissance du monde. Le problème suivant se pose : comment la pratique de la danse peut-elle être une stratégie dans le contexte éducatif pour le développement d'un corps plus conscient et attentif ? Une question qui est traitée à partir d'une méthodologie descriptive et réflexive basée sur la révision théorique des concepts du corps, du mouvement, des modèles culturels et pédagogiques et de la danse, pour finalement suggérer la pratique de la danse en tant que stratégie pédagogique optimale pour la construction d'un corps conscient et attentif.

\section{Mots clés}

Corps, danse, discipline, éducation, mouvement, reconnaissance corporelle.

\section{A prática dancística como uma estratégia dentro do contexto educativo para o desenvolvimento de um corpo mais consciente e atento}

\section{Resumo}

O Presente artigo aborda a prática dancística como um escape aos modelos do corpo imóvel construídos pela sociedade, reflexionando acerca das formas em que a dança pode ser um meio ótimo para o desenvolvimento do corpo em movimento que faz parte de todos os âmbitos da vida e cuja práxis pode ser introduzida nos sistemas educativos como um eixo transversal a aprendizagem e ao 
reconhecimento do mundo. Então se sugere o seguinte problema: Como a prática dancística pode ser uma estratégia dentro do contexto educativo para o desenvolvimento de um corpo mais consciente e revisão teórica dos conceitos do corpo, movimento, modelos culturais e pedagógicos, e dança, para finalmente sugerir a prática dancística como uma estratégia pedagógica ótima para a construção de um corpo consciente e atento.

\section{Palavras-chave}

Corpo, dança, disciplina, educação, movimento, reconhecimento corporal.

\section{Practica Dancística sug estrategiasina ukuma contexto educativo desarrollopepa sug cuerpomanda mas consiente y atento}

\section{Maillallachiska:}

Kai articulok aborda chi practica Dancistica mitikugsina modelos cuerpo mana kuiurri ruraska sociedadpe, iuiarrspa imasa danzak kangapaka sug medio suma cuerpo kuiurringapa ambitope kaugsaipe y chik churrangapa iachachiikunape sug eje transversalsina iachaikuipe reconocimiento kai mundope. Churrarenme negpek kai problema: ¿imasa practica dancistikak pódenme kanga sug estrategia sug cuerpok kacho mas consiente y atento? Cuestión ka tratareska sug metodología y descriptiva y reflexiva fundamentada kauaska teorica concepto cuerpo, kuiuriska, modelo cultural y pedagógico y danza, chasa nispak mañansapa practica dancística sug estrategia pedagógica suma iuñachinpaga sug cuerpo conciente y atento.

\section{Rimangapa Ministidukuna:}

Cuerpo, danza, disciplina, educación, kuiurii, reconocimiento corporal.

Desde su nacimiento y a lo largo de su vida existe en el hombre una gran sed de conocimientos, ansias de descubrir las formas en las que su cuerpo puede moverse y aprender. Prontamente, estas formas son moldeadas por patrones sociales y culturales que, en su afán por disciplinar, regular y homogeneizar, limitan este apetito de movimiento o sencillamente coartan el reconocimiento del cuerpo como parte del desarrollo del ser [Foucault, 2002; Paxton, 2011; Wooten, 2013].
Es evidente en la bibliografía antropológica, sociológica y filosófica que, en la historia de la humanidad, el cuerpo ha sido un lugar recurrente al que dirigir la mirada, estudiado para indagar sobre las formas en que el hombre habita el mundo. Así mismo, el cuerpo ha sido también el principal objeto de control, el canal para llegar a lo más profundo del individuo, la materia prima que puede ser moldeada para las necesidades específicas de la sociedad, el medio sobre el que se ejerce poder en busca de productividad. $Y$ todo esto se logra a través de vigilar, educar y corregir, como plantea 
Foucault [2002].

En este mismo sentido, se manifiesta la quietud del cuerpo como un modelo cultural y educativo que se presenta constantemente en las escuelas cuando los estudiantes deben pasar siete horas diarias en la misma posición atendiendo a sus clases. Sin embargo, los niños buscan liberar sus cuerpos y sus deseos de movimiento a través del juego mientras es aceptada esta conducta, ya que al crecer son cada vez menos las oportunidades o situaciones que el ser humano encuentra para saciar este afán de actividad corporal [Nussbaum, 2010; Paxton, 2011).

Entonces, la problemática es cómo son modelados los cuerpos de los infantes para los fines educativos, culturales y productivos [Foucault, 2002]. El presente artículo pretende abordar esta discusión, revisando los conceptos de cuerpo y movimiento, el movimiento como lenguaje corporal, los modelos culturales y pedagógicos dados en el contexto a tratar, la disciplina como dispositivo modelador del cuerpo, la danza como expresión artística y social, y, finalmente, la práctica dancística como un eje transversal al aprendizaje, como una estrategia pedagógica para el desarrollo de un cuerpo que se reconoce a sí mismo y a su entorno.

\section{Concepto de cuerpo}

Al hablar de cuerpo el panorama se hace enigmático y complejo, pues, además de ser un territorio vasto que precisa una mayor exploración, es también el lugar en el que convergen discusiones sobre sus modelos canónicos o grotescos, sus libertades o clausuras, sus usos o abusos, su politización y su medicalización, su sometimiento y su posesión, su unidad o su dualidad [Pera, 2006]. Esta última, sumada a la inevitable pregunta sobre la esencia que separa al cuerpo vivo del cuerpo muerto, en donde el concepto de cuerpo ha transitado a través de los tiempos y los pensadores con dilemas basados en la distinción o conjunción de las nociones de cuerpo y alma, cuerpo y mente, tener cuerpo o ser cuerpo [Pera, 2006; Pateti, 2008; Pineda, 2014).

En este sentido, a lo largo de la historia, se han dado diversas formas de comprender el cuerpo. Por ejemplo, para muchas civilizaciones precolombinas el cuerpo se halla en una estrecha unión con el mundo mismo, convirtiéndose en un cuerpo-mundo que está en relación con el todo [Andreella, 2010]. Por otra parte, para los griegos, la unión entre cuerpo y alma es lo que posibilita la vida del ser, por tanto, deben actuar juntas aun cuando el alma sea considerada la esencia vital del cuerpo. Para Platón estos conceptos poseen naturalezas completamente distintas, pues el cuerpo, materia inestable y corruptible, es la cárcel del alma, ideal, racional e intransmutable. Aristóteles reemplaza los términos por los de materia y forma, donde ambos permanecen unidos hasta el momento de la muerte, en el que desaparecen juntos. Sin embargo, continúa adjudicando al alma las funciones vitales [Pateti, 2008). Epicuro plantea que el cuerpo, biológico y sentiente, es el lugar desde donde se efectúa el lenguaje y el pensamiento, convirtiéndose en el centro de la existencia [Pera, 2006].

Más adelante, durante la modernidad, se instaura el pensamiento propuesto por Descartes, en el que el cuerpo es considerado sustancia regida por el espacio-tiempo y por causas mecánicas, mientras el alma deja de ser principio vital para concebirse como puro pensamiento (Pateti, 2008). Tales ideas, combinadas con una mirada cristiana del mundo, hicieron que, por un largo periodo de tiempo, en la civilización occidental se concibiera al cuerpo como materia propensa a ser corrompida y que por tanto era necesario acallar y negar, de ahí las primeras intenciones de inmovilizar al cuerpo para disciplinarle.

Posteriormente en Europa durante los siglos XVI y XVII, la idea de la fragmentación es perpetuada cuando el cuerpo es estudiado y entendido por partes (Pera, 2006). No obstante, para Spinoza, citado por Hardt [2004], el cuerpo es una unidad cuya existencia está basada en una incesante combinación de elementos que se hallan en caos y que se coordinan para conformar la estructura dinámica del cuerpo. En la postmodernidad, el cuerpo es cada vez más un objeto regido por la mente, aun cuando todo se concentra en el cerebro que continúa siendo cuerpo.

Desde otra perspectiva, Foucault [2002] habla de un cuerpo político que reúne los elementos materiales y técnicos de las relaciones de poder, convirtiéndose el cuerpo en un objeto de saber sobre el que se ejerce dominio. Del otro lado, el alma, es el lugar en el que se articulan las referencias de un saber que refuerza los efectos del poder. El alma habita al hombre empujándolo a la existencia, que es un dispositivo del poder que se ejerce sobre el cuerpo; y el alma es, en este caso, la prisión del cuerpo.

Así pues, como se evidencia en el anterior recorrido histórico por las nociones de cuerpo, se han dado espacios exclusivos para el entendimiento de alma y cuerpo de manera aislada; y sin alejarse de esto, el pensamiento mecanicista ha separado también los saberes que corresponden tanto a la mente como al cuerpo. En este sentido, Zaporah [2003] plantea que, aunque en algunas ocasiones parezca conveniente hablar de cuerpo y mente por separado, estos son en realidad dos elementos inseparables que conforman 
un todo, pues "el cuerpo se conoce a sí mismo a través de la mente y la mente se conoce a sí misma a través del cuerpo".

En esta misma línea, Grasso y Erramouspe [2005] proponen el concepto de corporeidad para aglomerar los aspectos físicos, biológicos, psíquicos, espirituales, sentimentales, motores, afectivos, sociales e intelectuales que conforman la construcción infinita del Yo identificado, del cuerpo dual que reúne mente y cuerpo en una unidad que interactúa con el contexto. Dicho esto, es claro que los significados dados al cuerpo implican siempre posturas sociales, filosóficas, teológicas, culturales y científicas propias del contexto que emite dicha definición.

Pero, ¿cómo definir al cuerpo sin condicionar o restringir el proceso de transformación infinito que es la identificación de cada ser humano? Desde la perspectiva del sentir, el cuerpo es el contenedor, el canal, el territorio que permite que el sujeto se relacione consigo mismo, con su organismo, con su esencia y con el mundo. Experiencia que es el fundamento de la sensación y la expresión del ser [Pineda, 2014]. En conclusión, se es cuerpo en permanente relación de fuerzas, afectos e intensidades, pues, como la identidad, un cuerpo no es estático ni terminado o completo, sino que es un proceso dinámico que acumula permanentemente sentidos nuevos y que está sujeto a cambios que buscan completar al ser como un individuo identificable y único, al cuerpo como territorio del Yo (Hall, 2003; Grasso y Erramouspe, 2005; Pera, 2006].

\section{El movimiento, el lenguaje del cuerpo}

Entendiendo al cuerpo como un terreno biológico vulnerable que es contenedor y testimonio del Yo en todas sus dimensiones, él no es solo un receptor de las variables del contexto que conforman su identidad, sino que es también el lugar desde el cual un individuo puede manifestarse, actuar o intervenir en el contexto mismo. De acuerdo con esto, Pera [2006], afirma que cada cuerpo revela su experiencia vital, percepciones de los contenidos del mundo e interacciones con otros cuerpos, comunicándose con lo que le rodea.

Por otra parte, el cuerpo mantiene un permanente reporte de su propio estado que actúa a través del sistema nervioso, mecanismo que es llamado cenestesia [Pera, 2006]. De modo que, así como el cuerpo es a su vez receptor y emisor en una relación de comunicación cuerpo-mundo, es también un interlocutor bidireccional en una comunicación cuerpocuerpo. Es decir que de la misma forma en que el cuerpo es intervenido por el contexto e interviene en el contexto, también tiene la capacidad de recibir información de su propio estado tanto como de alterarlo.

A esto mismo hacen referencia Grasso y Erramouspe [2005] cuando hablan del esquema corporal como una imagen mental del cuerpo en la que se identifica su forma, su espacio, sus límites, su orientación y sus sensaciones. Todo esto da como resultado una información del cuerpo codificada y útil para propiciar el movimiento, que toma como referencia una concepción de cuerpo en la que se tienen en cuenta los aspectos creativos y las infinitas variables de movimiento que el ser humano puede desarrollar.

Retomando lo dicho inicialmente, el cuerpo es medio de comunicación y además se comunica, constituyendo entonces un objeto semiótico, un conjunto de representaciones, significaciones, valoraciones, comprensiones y formas que se dan a través de diversos lenguajes como los gestos, las posturas y los movimientos. Es decir, el cuerpo es en sí mismo una representación, pues se expresa a su entorno y a los cuerpos en él a través de representaciones que manifiestan una construcción ideológica compleja (Pera, 2006; Bernard, 1980], pensamiento que se opone a la idea de mantener cuerpos inmóviles para educarles, teniendo en cuenta que la quietud es la "carencia de movimientos" (Real Academia Española, 2014] y estos son los primeros dispositivos comunicativos del cuerpo.

Así pues, es necesario situar el movimiento determinando en su origen, encontrando claridad en las condiciones del organismo que lo provee y vislumbrando el significado que este le atribuye. De esta forma, será posible comprender la forma que conlleva el movimiento, su configuración, su ejecución, su carácter representativo, su finalidad [Le Boulch, 1982].

El movimiento es entonces un lenguaje, y aunque sea considerado la materia prima de la danza, al igual que el color en la pintura o el sonido en la música, para Louppe [2011] el movimiento no obtiene valor en su originalidad ni en su composición espacio-temporal, sino en la energía que conlleva su experiencia. Para la coreógrafa y bailarina Isadora Duncan esto se traduciría en el placer producido por el lenguaje del cuerpo [el movimiento] comunicándose con el pensamiento más elevado [Sánchez, 2003], pues a lo largo de la vida el cuerpo registra sus experiencias más significativas y estas hacen parte del aprendizaje sensorial ligado al desarrollo dado en la infancia. Entonces el cuerpo es creador de los objetos que idea, proyecta y elabora, componiendo los caminos a la realidad y a la imaginación [Pera, 2006; Marín, 2006].

En tal caso, siendo el cuerpo el emisor y el movimiento el 
medio, es posible concebir la danza como la expresión plasmada de esta relación [Dewey, 2004). Pero, ¿por qué el cuerpo? Marín [2006] concibe el cuerpo como una entrada a lo experiencial y no solo como un fenómeno material; de manera que el arte y el cuerpo encuentran una estrecha relación en lo intenso de sus expresiones, en su singularidad, en la tensión entre significación y sinsentido, en el modo en que el arte reside en el cuerpo y este actúa a su vez como potencia del arte.

En conclusión, si se habla desde cierta clasificación de los elementos lingüísticos, "el movimiento es el elemento significante, el cuerpo es el soporte en que esos significantes operan, al servicio [o no] de determinados significados"

[Pérez, 2008]. En otras palabras, el arte de la danza es una experiencia dada por las formas del cuerpo que componen el movimiento [Sánchez, 2003], y la danza otorga al movimiento un contexto, que sería aquello que circunda al cuerpo e interactúa con él, afectando también al movimiento mismo.

\section{La cultura y las normas sociales}

La comprensión y aceptación del cuerpo, así como del movimiento, está ligada a la ideología y al contexto cultural y social de los individuos, por lo que es necesario comprender el comportamiento de estos a partir de la cultura en la que se desarrollan, delimitada por el lugar geográfico, el momento y las normas sociales específicas de los mismos.

Pero, para hablar de cultura es necesario citar a Tylor quien, en el siglo XX, la define así:

La cultura es el conjunto de las modalidades de la experiencia social, construidas sobre unos saberes aprendidos y organizados como sistemas de signos, dentro de una comunicación social que proporciona a los miembros de un grupo un repertorio y constituye un modelo de significaciones socialmente compartidas que les permiten comportarse y actuar de manera adaptada en el seno de una sociedad. [Tylor en Fischer, 1992: 20]

En relación a esto, la dimensión social de la cultura explica cómo los miembros de un mismo grupo generan acuerdos tácitos sobre la forma adecuada de comportarse en cada situación, convirtiéndose en parte del contenido cultural de un grupo. Es así que, aun cuando hay comportamientos individuales, el colectivo crea sus propios acuerdos; se puede entonces concluir que la cultura reúne todas las formas sociales de interacción entre los individuos que comparten un tiempo y espacio en la historia [Fischer, 1992].

En consecuencia, el sistema escolar se convierte no solo en un transmisor de los valores culturales, sino en un controlador de estos, decidiendo qué comportamientos se reprimen y cuáles deben ser reforzados, como lo muestra Toro en el 2008 a través de una revisión de casos documentados en colegios chilenos de finales del siglo XIX, encontrando cómo el castigo del cuerpo se convierte en un medio para la imposición de la disciplina. El encierro, los golpes y los azotes llegan a ser prácticas tan comunes y aceptadas por la sociedad que se vuelven parte de la cultura escolar de la época; el autor precisa que, aunque este tipo de conductas fueron cambiando en el siglo XX por una pedagogía más racional, el propósito de mantener la disciplina del cuerpo continúa a través de nuevas configuraciones.

Es así como, en el ámbito escolar, prevalece una cultura dada por la escuela tradicional basada en el autoritarismo y la formalidad, lo que ha sido llamado "cultura escolar", donde mandan el orden, la obligación y el cumplimiento del deber a través del temor a la sanción. Estas prácticas dan como resultado un estudiante pasivo, apegado a rutinas sin sentido, indiferente, conforme y dador de respuestas esperadas por la norma. Esto, a su vez afecta la capacidad de reflexión y elección, y el desarrollo de su propia identidad basada en las motivaciones personales, resultando un estudiante "disciplinado" y en consecuencia estático, desde el cuerpo hasta las ideas [García y Vanella, 2002).

Para abordar el concepto de disciplina es importante reconocer su origen etimológico, ya que al derivarse del vocablo en latín "discipulus", permite comprender el significado más natural y reconocido socialmente, de sometimiento, subordinación u obediencia de alguien que recibe algo o aprende de otro. Es de allí de donde se acepta el término para determinar disposiciones de pensamiento grupal, que inhiben el individual y llevan al ser humano a renunciar a su libertad de pensamiento para asumir una posición colectiva [Ospina, 2004].

La disciplina, entonces, se convierte en una fórmula general de dominación y es explicada desde el cuerpo, que es sometido, instigado, dominado sin necesidad de fuerza, violencia o ideología, por medio de tres formas de disciplina para el cuerpo: ejercer una sujeción débil sobre cada una de las partes del cuerpo, cambiar el objeto de control llegando a dominar los movimientos y su organización interna; y, finalmente, dominar constantemente sobre los procesos del cuerpo [Foucault, 2002].

Dentro de la cultura escolar, la disciplina ha cambiado su propósito: pasó del castigo del cuerpo a la vigilancia de un sano desarrollo del niño en sus dimensiones psíquica 
y afectiva. Tal y como lo propone Rengifo y Cols. [2016], la "escuela ya no está hecha para disciplinar en sentido estricto [militar] está estructurada, pensada y proyectada para estimular habilidades, destrezas, competencias" [p. 348]; la disciplina escolar del siglo XXI, aun cuando su fin ya no es inmovilizar el cuerpo, a través de otros medios convierte al educando en un ente inmóvil con un gran cúmulo de conocimientos socialmente aceptados y avalados por la normatividad de la educación.

\section{La educación y las artes}

Para el Ministerio de Educación Nacional [2000], la educación artística tiene como finalidad el desarrollo de la experiencia sensible y estética, la creatividad y la expresión, o en sus palabras:

La educación artística es un área del conocimiento que estudia [...] la sensibilidad mediante la experiencia [experiencia sensible] de interacción transformadora y comprensiva del mundo, en la cual se contempla y se valora la calidad de la vida, cuya razón de ser es eminentemente social y cultural, que posibilita el juego en el cual la persona transforma expresivamente, de maneras impredecibles, las relaciones que tiene con los otros y las representa significando la experiencia misma [Ministerio de Educación Nacional [MEN], 2000: 25]

Respondiendo a los lineamientos nacionales, Bogotá ha sido ejemplo con el "Proyecto Jornada 40x40 para la excelencia académica y la formación integral", que busca el desarrollo integral de los educandos a través de la inclusión de la cultura, el arte y el deporte dentro del programa académico de los colegios, recibiendo de manera gratuita educación artística, actividad física, recreativa y deportiva, con el fin de despertar su creatividad, sensibilidad y expresión corporal [Proyecto Jornada 40x40 para la excelencia académica y la formación integral, s.f.].

No obstante, a pesar de que tanto el ministerio como las propuestas distritales apuestan por una educación artística que favorezca la creatividad y la sensibilidad, proponen una didáctica que se desarrolla a través de la imitación, la ejercitación y la indagación [MEN, 2000], siendo esta última la única que propicia un escenario con posibilidades expresivas en las que el estudiante pueda descubrir nuevos lenguajes, técnicas y conocimientos. Por el contrario, incluir estrategias como la imitación y la ejercitación en la escuela podrían convertirse en factores que no permitan reconocer al cuerpo como mediador del aprendizaje, encontrándose con obstáculos como la exclusión mutua entre lo físico y lo intelectual, adjudicando toda la responsabilidad del estudio del cuerpo a una práctica mayormente deportiva, de este modo la educación iría negando progresivamente al cuerpo y su movimiento, olvidándolo, fragmentándolo y limitando sus posibilidades [Pateti, 2008).

\section{El movimiento convertido en danza}

Al pensar en la danza como un medio para la integración del cuerpo hay que comenzar por comprender lo que ella en sí misma implica, pero infinitas discusiones giran hoy en día en torno a la definición de danza, y aunque parezca imposible dar una aclaración última de su significado, es posible acotar criterios que permitan ilustrar aquello que compone el espacio o conjunto de relaciones actualmente concebido como danza. Sánchez [2003], citando a Duncan, dice que la danza "trasciende lo puramente estético, propone un modelo de comportamiento", porque los movimientos que la componen provienen primeramente de la naturaleza. Pero, ¿significa eso entonces que todo en la naturaleza es o hace danza? Ante este cuestionamiento, Pérez [2008] diría que para definir la danza hay que comenzar por descartar aquellas ideas poéticas en las que todo puede ser danza o todo puede danzar, de modo que un primer discernimiento podría ser que en la danza participan cuerpos humanos en movimiento, siendo esto último, el movimiento, con sus características de flujo, energía, espacio y tiempo, la materia prima del acto danzado.

Beardsley [1979, citado por Banes, 1994] propone que es de dominio de la danza el movimiento que exhibe cierta superfluidez de expresividad. Es decir, aquello que se desborda en fuerza y magnificencia. Pero a esta definición se opone Banes (1994), argumentando que dicha superfluidez de expresividad no es un requisito para que algo sea danza en tanto muchas acciones cotidianas pueden darse con esa característica y no ser consideradas danza, o mucha danza puede tener como razón de ser presentar el movimiento como algo ordinario o mundano. Pera [2006] trata este tema, señalando que el cuerpo humano es siempre objeto de apreciación de otros en sus actuaciones cotidianas. Sin embargo, cuando dichas actuaciones buscan intencionalmente la atención se convierten en arte para ser contemplado.

En otras palabras, "la danza sería una técnica del cuerpo", teniendo en cuenta que los movimientos que la conforman provienen de movimientos con finalidades específicas en la cotidianidad y son transformados para componer nuevas formas que deben ser entrenadas y cuya finalidad es el arte [Barba, 2002). Pero, si bien es cierto que la danza puede pensarse a partir de sus valores técnicos, también es cierto que no es solo técnica, pues incluye también las necesidades 
expresivas propias de una manifestación artística que instiga a la reflexión, investigación, experimentación, creación, práctica e interpretación (Marín, 2009; Viana, 2009].

Nótese, entonces, que teniendo en mente estas concepciones de danza, se puede pensar en dos prácticas sociales diferenciadas que le competen: la danza-arte y la danza social, y en general ambas coinciden en que el momento y el contexto en que se dan es más importante que la naturaleza misma del movimiento para ser consideradas danza.

No obstante, hay ciertas distinciones claras: en el caso de la danza como expresión artística, la motivación principal es la contemplación estética de la que toman parte los tres agentes que se relacionan en la experiencia creativa, interpretativa y apreciativa de la danza: el coreógrafo [poseedor de la imagen significante, de la idea]; el intérprete [cuerpo que opera como soporte del concepto y la representación]; y el público [ente decodificador en cuya experiencia receptiva es conmovido] (Pérez, 2008). Del otro lado, la danza como demostración social es producto de una actividad ritual, social o cultural que se prolonga hasta sus significaciones sociológicas o antropológicas más profundas [Banes, 1994]. Como manifestación cultural de un colectivo, grupo e incluso de una nación, la danza se ve permeada por la búsqueda de una identidad o identificación que la haga única, haciendo uso de una postura social-política clara y definida [Hall, 2003].

\section{Discusión}

Hablar de danza como manifestación cultural y artística dentro del contexto colombiano propone identificar elementos propios de la tradición y de la historia de donde proviene, reconocer la formación de una posible identidad cultural de la nación, reflexionar sobre los modelos culturales vigentes [Hall, 2003], promover modelos educativos que satisfagan las necesidades de los cuerpos colombianos e introducir estrategias de la práctica dancística que sean adecuadas para el desarrollo consciente de los cuerpos que habitan este territorio.

Con este propósito, la danza tiene como responsabilidad señalar y reciclar el aprendizaje corporal que la práctica cotidiana puede brindar, centrándose en los procesos cognitivos y afectivos del individuo que se mueve dentro de un contexto lleno de tradiciones, valores y modelos claros, más que en los procesos físicos del mismo, pues de este modo se construye un imaginario de cuerpo completo, integral, cuya confianza se encuentra basada en la comprensión de sus posibilidades y limitaciones que le permitirán resolver eficazmente los retos a los que a diario se enfrenta el cuerpo [Grasso y Erramouspe, 2005].

Esta reflexión conduce a pensar en la danza no solo como una expresión física o artística sino como una manifestación del lenguaje ${ }^{1}$ del cuerpo, expuesto en su permanente proceso de identificación y reconocimiento; y es aquí donde Louppe [2011] propone que danzar no implica exclusivamente la manipulación de movimientos preexistentes, ya codificados, sino que merece el riesgo de la invención, de crear el material que hará parte de este lenguaje.

Entonces, proponer la danza como medio que permita el reconocimiento del cuerpo, no solo requiere del establecimiento de una estrategia de enseñanza y una didáctica clara que hagan parte de los currículos de la educación colombiana, sino de comprender la necesidad de aceptar la creatividad y la imaginación como elementos fundamentales del desarrollo y reconocimiento de la corporeidad. En este sentido, como propone Zambrano [2005], al hablar de didáctica se pretende incitar a los sistemas educativos a promover una forma eficaz en la que el docente emita el saber a sus estudiantes permitiendo estructurar el conocimiento transmitido a través de interacciones entre los individuos y el objeto por conocer.

Siendo así, hay que reconocer el arte como un medio para continuar involucrado con la imaginación y, por supuesto, con la creatividad, ya sea a través de la interpretación del artista o de la perspectiva del observador. Esta es la posibilidad permanente que tiene el ser humano para sensibilizarse en la creación a partir del autoconocimiento y el conocimiento y aceptación de los demás [Nussbaum, 2010].

Se podría entonces concluir que cuando se quiere educar, desde un campo científico hasta un campo artístico, es necesario comprender que la técnica es importante pero que ella está subordinada a la expresión imaginativa, para lo cual es necesario plantearse la siguiente reflexión: ¿qué tanto se parece lo que hago a lo que quería hacer? Es decir, lograr la conexión con la vida, con lo que se siente, la relación con la técnica, los intereses de quien aprende, la exigencia a la que se enfrenta y la posibilidad de aprender de otros [Dewey, 2004]. En otras palabras, como lo plantea el bajista y compositor Victor Wooten [2013], en el arte, no ser forzado a practicar, no recibir órdenes sobre lo que se debe hacer y usar lo aprendido inmediatamente en el contexto sin

1 Entendiendo el lenguaje como un "sistema articulador de convenciones entre individuos que posibilita la práctica social" [Ribes-Iñesta, 2007]. 
tener que ensayar antes de apropiarse de ello, es la manera en que se puede conservar la libertad, algo con lo que todos los niños nacen y muchos artistas pasan demasiado tiempo tratando de recuperar después de haber sido despojados de ella al crecer y hacer parte del modelo educativo vigente.

De este modo, hay que señalar que el proceso de aprendizaje se concibe como la adquisición de una habilidad o un conocimiento a partir de una experiencia que es luego atravesada por el razonamiento. En esa medida se diría que, para conseguir aprender, cada sujeto, desde su individualidad, hace acopio de distintos métodos que le permitan decodificar la información de la manera que le sea más precisa [Morales, 2013). Lo que sería viable, de acuerdo a Samaja [1996], si la educación permitiera el pensamiento abstracto, el modelado y la simulación como elementos propiciadores del pensamiento creativo, pues la educación formal se sustenta en el hacer y en el saber hacer.

Entonces, no puede pensarse en una fórmula única de acercarse al lenguaje del cuerpo que sea funcional para todos los individuos, sino que debe propiciarse un espacio de libertad en el que sean reconocidas las particularidades para que cada cuerpo sea su propio maestro, asiéndose de las herramientas que naturalmente le son dadas, como la necesidad innata de moverse, de explorarse, de descubrirse, o como el placer inevitable que produce la más básico de las expresiones artísticas.

De manera que, si es la danza una estrategia para comprender el cuerpo, para habitarlo conscientemente, para tornar la atención a él sobreponiéndose a los modelos que lo inmovilizan, niegan o acallan, ¿cuáles son los caminos que la educación podría tomar para sobreponer la experiencia reflexiva de la danza al trabajo técnico y mecánico del cuerpo que busca modelar con restricciones o con patrones fijos y homogeneizadores?

\section{Referencias}

Andreella, F. [2010]. El cuerpo suspendido. Códigos y símbolos de la danza al principio de la modernidad. [Trad. D. Ponce]. México D.F.: Instituto Nacional de Bellas Artes y Literatura.

Banes, S. [1994]. Writting Dancing in the Age of Postmodernism. Hanover: Wesleyan University Press.

Barba, E. [2002]. “Le corps crédible”. En Aslan, Odette [Comp.], Le corps en jeu, Paris, CNRS Éditions.

Bernard, M. (1980). El cuerpo. Buenos Aires: Paidós.
Dewey, J. [2004]. Democracia y ciudadanía. Madrid: Ediciones Morata

Fischer, G. (1992). Campos de intervención en psicología social. Madrid: Grupo-Institución-Cultura-Ambiente social; Narcea.

Foucault, M. [2002]. Vigilar y castigar: nacimiento de la prisión. Buenos Aires: Siglo XXI.

García, S. y Vanella, L. [2002]. Normas y valores en el salón de clases. México: Siglo XXI.

Graham, M. [1973]. The Notebooks of Martha Graham. New York: Houghton Mifflin Harcourt.

Grasso, A. y Erramouspe, B. [2005]. Construyendo identidad corporal. La corporeidad escuchada. Buenos Aires: Novedades Educativas.

Hall, S. [2003]. Cuestiones de identidad cultural. Buenos Aires: Amorrortu.

Hardt, M. [2004]. Deleuze. Un aprendizaje filosófico. Buenos Aires: Paidós.

Le Boulch, J. [1982]. Hacia una ciencia del movimiento humano. Buenos Aires: Paidós.

Lineamientos Curriculares de Educación Artística [2000] Ministerio de Educación Nacional MEN. Recuperado en www. mineducacion.gov.co

Louppe, L. [2011]. Poética de la danza contemporánea. [Trad. A. Fernández] Salamanca: Ediciones Universidad de Salamanca.

PMid:21643789

Marín, S. [2006]. Pensar desde el cuerpo. Tres filósofos artistas: Spinoza, Nietzsche y Pessoa. Tijuana: DDO Producciones.

Marín, A. [2009]. "La danza como 'medio puro': Más allá de la técnica”. En P. Chaves, N. Orozco, M. Roa, \& Asociación Alambique [Edits.], La danza se lee (p. 34-44]. Bogotá: Orquesta Filarmónica de Bogotá.

Morales, R. [2013]. "Cambios generados en los razonamientos deductivo e inductivo a partir de la implementación del aprendizaje basado en problemas para la formación de psicólogos". Tesis de maestría en psicología. Universidad Católica de Colombia. Bogotá, Colombia. 
Nussbaum, M. [2010]. Sin fines de lucro: por qué la democracia necesita de las humanidades. Uruguay: Pressur Corporation S.A.

Ospina, C. [2004). “Disciplina, saber y existencia”. Revista latinoamericana: ciencias sociales, ni-ez y juventud, 2 [२], 51-81.

Pateti, Y. [2008). Educación y corporeidad. La despedagogización del cuerpo. Armenia: Kinesis.

Paxton, S. [2011, 3 de septiembre]. "About Dancing" [Archivo de video]. Video dirigido a https:/ / www.youtube. com/watch?v=VDBbyypWLJM

Pera, C. [2006]. Pensar desde el cuerpo. Ensayo sobre la corporeidad humana. Madrid: Triacastela.

Pérez, C. [2008]. Proposiciones en torno a la historia de la danza. Santiago: LOM.

Pineda, A. [2014]. "Del cuerpo al sentido". En C. Sanabria, \& A. Ávila [Edits.], Pensar con la Danza [p. 185-194]. Bogotá: Ministerio de Cultura, Colombia; Universidad de Bogotá Jorge Tadeo Lozano.

Proyecto Jornada 40x40 para la excelencia académica y la formación integral [s.f.]. Recuperado el 28 de noviembre de 2016, de http:/ / nubr.co/6zoDFI

Real Academia Espa-ola. [2014]. Diccionario de la

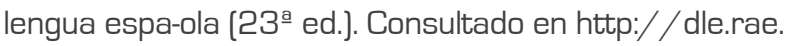
es/?id=FdIOOOr

Rengifo, J.; Pinillo, E.; Díaz C.. [2016]. "La paradoja del espacio académico: disciplinar sin disciplina”. En Revista Colombiana de Educación, Enero-Junio, 341-359.

https:/ / doi.org/10.17227/01203916.70rce341.359

Ribes-l-esta, E. [2007]. “Lenguaje, aprendizaje y conocimiento". Revista mexicana de psicología. Junio, p. 7-14.

Samaja, J. [1996]. Sobre el lugar de la abducción y la analogía en la creación cognitiva. F. Psicologia. UBA. Buenos Aires.

Sánchez, J. A. [Ed.]. [2003]. El arte de la danza y otros escritos. Madrid: Ediciones Akal, S.A.

Toro, P. [2008]. "Disciplina y castigos: fragmentos de la cultura escolar en los liceos de hombres en Chile en la segunda mitad del siglo XIX". En Cuadernos Interculturales, segundo semestre, 127-144.

Viana, L. [2009]. "Insumos para hablar de danza”. En P. Chaves, N. Orozco, M. Roa, \& Asociación Alambique [Edits.], La danza se lee [p. 67-73]. Bogotá: Orquesta Filarmónica de Bogotá.

Wooten, V. [2013, 29 de mayo]. "Music as a Language". Gabriola Island: TEDxTalks. Video dirigido a https:/ / www. youtube.com/watch?v=2zvjW9arAZO

Zambrano, A. [2005]. Didáctica, pedagogía y saber. Bogotá: Magisterio.

Zaporah, R. [2003]. "Dance. A Body with a Mind of its Own". En A. Cooper \& D. Gere [Edits.], Taken by Surprise. A Dance Improvisation Reader. [p. 21-24). Middletown: Wesleyan University Press.
Laura Oyuela. Fotógrafía: Daniel Gutierrez Bohorquez. 2017 